\title{
Contributos para a clarificação do conceito de competência numa perspetiva integrada e sistémica
}

\author{
Patrícia Sá
}

Universidade de Aveiro, Portugal

Fátima Paixão

Instituto Politécnico de Castelo Branco, Portugal

Resumo

Neste artigo temos como principal finalidade contribuir, através da análise reflexiva de perspetivas avançadas por diferentes autores (Allal, 2004; Alonso, 2006; Escamilla, 2009; Jonnaert, 2002; Le Boterf, 2005; Legendre, 2000; Perrenoud, 1999, 2001; Roldão, 2005a; Rychen \& Tiana, 2005; entre outros), para a clarificação da noção de competência, assumindo uma perspetiva integrada e sistémica do conceito. Pretendemos, deste modo, colaborar para o esclarecimento de uma perspetiva global e integradora desta noção, que assuma as suas múltiplas dimensões, conteúdos e elementos no sentido da sua utilização partilhada, de modo mais incidente no domínio da Educação. Para tal, após uma curta introdução, o presente artigo defende a importância da clarificação conceptual da noção de competência, apresenta uma breve evolução do conceito e sistematiza as principais divergências e convergências encontradas nos entendimentos avançados pelos autores analisados.

Palavras-chave

Competência; Evolução do conceito; Perspetiva integrada e sistémica

\section{Introdução}

A visibilidade que o conceito de competência tem assumido a nível nacional e internacional, nas últimas décadas, em educação, evidencia um 
novo entendimento do papel da escola e da formação face a uma sociedade em constante mudança, alicerçada na complexidade e imprevisibilidade. No entanto, a falta de uma definição mais concisa da noção de competência e o excesso de entendimentos que proliferam têm-se vindo a revelar condições indutoras de confusão terminológica e conceptual e evidenciam a necessidade e urgência de clarificação do conceito.

Utilizado pela Psicologia, pela Sociologia, pela Linguística, pelas Ciências do Trabalho e pelas Ciências da Educação, o conceito de competência tem vindo a ser objeto de múltiplas definições e interpretações, mudando de sentido de acordo com o domínio em que é utilizado e o contexto a que se refere. Ropé e Tanguy (1997) evidenciam o caráter polimorfo do conceito de competência. Weinert (2001) salienta a inflação conceptual de que é alvo. Pires (2005) e Gouveia (2007) não deixam de sublinhar a sua polissemia, referindo-se o último a uma "nebulosa conceptual". Jonnaert (2002) refere-se à competência como conceito "nómada" e "volátil" e Le Boterf (1999) apelida-o de "camaleão conceptual".

Reconhecida que é, por vários autores, a diversidade conceptual e a variedade terminológica do conceito, admitimos que perspetivas claras sobre competência são mais necessárias do que nunca. No entanto, a construção de um entendimento comum depende, em grande parte, da criação de uma linguagem partilhada a nível internacional. Para tal, consideramos fundamental proceder à análise sistemática de abordagens teóricas e conceptuais existentes. É, assim, finalidade deste estudo contribuir, através da análise reflexiva das perspetivas de vários autores, para a clarificação da noção de competência, procurando apresentar, de forma fundamentada, uma abordagem integrada do conceito que permita ultrapassar as limitações das abordagens analíticas (mais tradicionais) que entendem a competência como resultado, objetivado em termos de desempenho. Pretendemos, deste modo, colaborar para o esclarecimento de uma perspetiva global e integradora de competência, que considere as suas múltiplas dimensões, elementos e conteúdos no sentido de uma utilização partilhada (mais útil), de modo mais incidente no domínio da Educação. 


\section{O interesse da clarificação conceptual de competência}

O desenvolvimento científico-tecnológico que se tem vindo a acentuar a partir da segunda metade do século $X X$ contribuiu para a aceleração, produção e reconfiguração da informação, dificultando qualquer ideia de certeza, continuidade ou permanência (Cachapuz, Sá-Chaves, \& Paixão, 2004; Eurydice European Unit, 2002; Galvão, Reis, Freire, \& Oliveira, 2006; Morin, 1999). As sociedades contemporâneas são caracterizadas pela complexidade e imprevisibilidade. Preparar os cidadãos para a constante mudança é uma exigência da sociedade a fazer à escola e a ser assumida por esta. É fundamental que os cidadãos compreendam a incerteza do real, a dimensão científico-tecnológica dos problemas que enfrentam e intervenham de modo refletido e solidário, numa perspetiva transnacional e conscientes da dialética entre o local e o global (Morin, 1999; Santos, 2005). Já o Relatório da UNESCO para a Comissão Europeia Educação: Um tesouro a descobrir (Delors et al., 1996) partilhava desta posição, assumindo "o dever de se preparar para a mudança" como "uma das responsabilidades fundamentais da educação".

Contudo, a escola que temos não tem servido esta sociedade. Vários investigadores (Alonso, 2006; Cachapuz et al., 2004; Gouveia, 2007; Roldão, 2003; Tardif, 1999; Tiana, 2005, cit. em Rychen \& Tiana, 2005; entre outros) enfatizam o desajuste que se verifica entre a aceleração do conhecimento científico-tecnológico das sociedades modernas e a definição e desenvolvimento de políticas educativas capazes de apoiar a mudança para a sociedade do conhecimento. Ou, a um outro nível de análise, o evidente desfasamento entre o contexto formal de ensino e aprendizagem (escola) e as exigências do atual mercado de trabalho. O contexto económico evoluiu, no período anteriormente considerado, de uma economia centrada no fator produção para uma economia centrada no fator mercado (Canavarro, 2000). Nesta, há uma valorização do capital imaterial (conhecimento), tornando-se a qualidade dos recursos humanos um fator estratégico (Gouveia, 2007; Tiana, 2005, cit. em Rychen \& Tiana, 2005).

A questão da influência da necessidade do exercício de vida política, social e cultural por cada indivíduo e das novas exigências do mundo 
produtivo na definição das competências a desenvolver pela ação educativa é, também, abordada por Alonso (2006). A autora enfatiza a falta de significatividade e de funcionalidade das aprendizagens escolares, bem como a falta de relevância destas aprendizagens para as várias dimensões da vida quotidiana dos cidadãos (social, laboral, relacional, cultural,...). Tal ideia é partilhada por Roldão (2003), que evidencia a alegada ineficácia da escola e a crescente exigência dos mercados de trabalho quanto às competências dos profissionais, fatores apresentados pela autora como justificações para a reemergência da abordagem por competências em contexto escolar.

Para além dos argumentos apresentados para a relevância da abordagem por competências - complexidade e imprevisibilidade do mundo atual, desfasamento entre a formação académica e as exigências do mercado de trabalho e um novo paradigma educativo -, o Ministério da Educação do Québec (2001) acrescenta, ainda: i) a perspetiva demasiado analítica dos programas escolares, que reforçou a proliferação de objetivos, o parcelamento dos conhecimentos, a atomização das competências, a ênfase nos objetivos a curto prazo, nas capacidades elementares em vez de competências mais complexas e na avaliação em vez de na aprendizagem; e ii) a influência da formação profissional na formação geral, no sentido da definição de uma perspetiva mais pragmática e relacional do saber.

\section{A evolução do conceito de competência}

Face à pertinência do esclarecimento conceptual de competência, procedeu-se à análise da evolução deste conceito. Embora outros critérios pudessem ter sido usados para estruturar a apresentação da referida análise, a evolução do conceito organizar-se-á de acordo com as abordagens dominantes que, desde o início deste debate (final da década de 50 do século passado), foram emergindo nos Estados Unidos da América (EUA) e na Europa.

\subsection{Abordagem behaviorista de competência}

Historicamente, White (1959, cit. em Delamare Le Deist \& Winterton, 2005) é identificado como o responsável pela introdução, nos EUA, do termo competência, referindo-se às características pessoais associadas a um 
desempenho superior na realização de uma tarefa e à motivação com que o indivíduo a realiza (Delamare Le Deist \& Winterton, 2005). Posteriormente, e seguindo a abordagem de White, McClelland (1973), na sua publicação Testing for Competence rather than Intelligence, define a competência como uma característica subjacente ao sujeito, casualmente relacionada com desempenho superior na realização de uma tarefa ou em determinada situação (Delamare Le Deist \& Winterton, 2005; Fleury \& Fleury, 2001). Para além de precisar a noção de competência, o referido autor, na mesma publicação, distingue, ainda, aptidões (que define como talento natural e pessoal), habilidades (consideradas a demonstração prática do talento particular, isto é, das aptidões) e conhecimentos (que considera serem aquilo que as pessoas precisam de saber para desempenhar uma determinada tarefa), num exercício de clarificação conceptual e terminológica do conceito.

$\mathrm{Na}$ literatura de referência, McClelland tem vindo a ser referido por diversos autores (Delamare Le Deist \& Winterton, 2005; Fleury \& Fleury, 2001; Gouveia, 2007; Rychen \& Salganik, 2001) como precursor de uma perspetiva mais clássica da noção de competência: competência entendida como input. Assim, no início da década de 70 do século XX, nos EUA, entre as abordagens mais expressivas destacava-se a behaviorista, assente na valorização dos aspetos observáveis da competência (desempenho/ comportamento diretamente observável). No sentido de ilustrar a importância que esta abordagem atribui ao comportamento observável relacionado com determinada tarefa, Pires (2005) recupera Hager \& Gonczi (1996) nas suas críticas ao behaviorismo:

A competência é concebida em termos de comportamentos separados, associados com a finalização de tarefas atomizadas. (...) Esta abordagem não valoriza as relações entre as tarefas e ignora a possibilidade de que o conjunto das tarefas pode conduzir à sua transformação (Pires, 2005, p. 289).

De acordo com a perspetiva behaviorista, uma competência existe quando se evidencia e manifesta através de um comportamento que seja passível de ser diretamente observado e medido. As competências deveriam, assim, ser caracterizadas através de indicadores comportamentais, da forma mais operacional possível, particularizando ações específicas. Face ao exposto, Hager (2005, cit. em Silva, 2009) considera esta perspetiva atomista, redutora, mecanicista e estandardizada. O autor defende que, ao estar 
baseada em tarefas rotineiras, reforça a uniformidade do desempenho e conduz à identificação de um grande número de competências específicas, operacionalizadas pela definição de comportamentos isolados e necessários à realização de determinada tarefa.

Sob a influência desta abordagem surgem, nos Estados Unidos da América e no Reino Unido, programas de formação de professores centrados na aquisição de competências entendidas como comportamentos diretamente observáveis que tivessem uma correlação positiva com o aumento ou a melhoria dos resultados dos alunos: o Competency Based Teacher Education (CBTE) e o Performance Based Teacher Education (PBTE). Swanchek \& Campbell (1981, cit. em Esteves, 2009) referem a especificação precisa das competências ou comportamentos a serem aprendidos, a modularização da instrução, a avaliação e o feedback, a personalização e a experiência de campo como os principais traços dos referidos programas. A seleção das competências era feita de entre os comportamentos que a investigação científica de base experimental tivesse mostrado que estavam positivamente correlacionados com as aprendizagens dos alunos (Esteves, 2009, p. 39). As críticas ao CBTE e ao PBTE foram permanentes, tornando-se mais incisivas a partir da década de 80 do século XX. Dois argumentos foram invocados de modo recorrente: a inadequação da definição analítica das competências para retratar o perfil dos profissionais mais bem-sucedidos e a falta de evidências científicas que corroborassem a superioridade destes programas em relação a outros (Esteves, 2009).

Ainda durante a década de 80, o Governo do Reino Unido, no sentido de estabelecer um sistema nacional unificado de qualificações baseado no contexto laboral, criou o National Vocational Qualifications (NVQ). As qualificações vocacionais criadas sob este quadro de referência eram baseadas em padrões estandardizados de competências, fundamentados em análises funcionais de ocupações realizadas em diversos contextos. No NVQ, os padrões ocupacionais identificam papéis-chave que se encontram subdivididos em várias unidades de competência. Posteriormente, estas unidades subdividem-se em vários elementos de competência e, para cada um destes, são definidos critérios de desempenho, que formam a base da avaliação. Delamare Le Deist e Winterton (2005) consideram que esta é uma abordagem funcional ao conceito de competência, distinguindo-a da 
behaviorista pela particularidade do contexto para o qual são definidas as competências.

Apesar de ter sido uma perspetiva dominante, a perspetiva behaviorista da competência mostrou-se claramente insuficiente para uma compreensão mais alargada do agir humano, sendo alvo de várias críticas (Gouveia, 2007), nomeadamente:

i) ser reducionista: a decomposição de uma função em várias tarefas, atividades e comportamentos só é possível com baixos níveis de complexidade (onde é mais fácil estabelecer relações do tipo causal entre comportamentos e desempenho);

ii) ser rígida: a listagem de comportamentos que evidenciem a competência pode inibir formas alternativas de obter o mesmo resultado;

iii) ser centrada nos comportamentos: não tem em conta aspetos tão importantes para a compreensão da complexidade da competência como os valores, as motivações, o autoconceito e os traços da personalidade; e

iv) ser independente do contexto: a competência é vista como não sendo afetada pelas caraterísticas do contexto onde se manifesta.

Em síntese, por um lado, esta abordagem não considera a competência enquanto realidade complexa, dinâmica e globalizante e, por outro, focando-se num produto final (comportamento diretamente observável e mensurável), desvaloriza outros aspetos, menos objetiváveis (Silva, 2009) mas fundamentais para a sua compreensão, tais como as dimensões cognitiva, afetiva, social e relacional (Hager \& Gonczi, 1996).

\subsection{Abordagem integrada de competência}

Na linha da complexidade e da sistémica, Sá-Chaves (1994) sublinha o duplo sentido da noção de competência: i) por um lado, surge como comportamento específico ou desempenho, que pode ser observado e demonstrado e, por esta razão, avaliado; e ii) por outro lado, embora ainda dentro de um quadro de tendência atomista, 
qual subjaz uma análise de factores que determinam a pertinência dos objectivos e a tomada de decisão quanto à natureza do dito comportamento, de modo a facilitar a sua consecução eficaz (p. 64).

É também na mesma linha que Le Boterf (1999) afirma que o sentido mais tradicional da noção de competência já não permite compreender os novos desafios colocados pelo século XXI. Neste novo contexto de um mundo em que a complexidade e a interdependência são características dominantes, terá de se abandonar o âmbito mais tradicional da noção de competência. $O$ conceito terá de ganhar novos contornos, tornar-se pluridimensional. $O$ autor situa a competência no centro da interação entre três eixos: a pessoa (definindo uma dimensão de pessoalidade), a sua formação (no sentido mais académico) e a sua experiência profissional. A noção de competência é, por ele, perspetivada como uma disposição para agir de modo pertinente em relação a uma situação específica, exigindo saber coordenar operações e não somente aplicá-las isoladamente, o que remete para "saber combinatório" e definição contextualizada da competência. Este saber combinatório pode ser entendido à luz do triângulo saber agir, querer agir e poder agir.

Adicionalmente, Le Boterf (cit. em Gouveia, 2007) enfatiza a necessidade da adoção de uma abordagem conceptual de competência que:

i) vá ao encontro das evoluções do contexto e das situações do trabalho;

ii) dê conta da dupla dimensão individual e coletiva (embora as competências se refiram às pessoas, dependem do contexto profissional e das redes que aí se estabelecem);

iii) evidencie a necessidade de considerar a competência não apenas como uma disposição para agir, mas igualmente como um processo;

iv) conduza a um raciocínio em termos combinatórios e não apenas em termos de adição;

v) permita ter presente a diferença entre competência exigida e competência real;

vi) faça apelo a uma responsabilidade partilhada (a responsabilidade da construção das competências não se reduz ao indivíduo); e

vii) torne possível a sua avaliação. 
Neste sentido, para Le Boterf (2005) a noção de competência deverá promover a articulação entre diversos domínios: dos saberes à ação (a competência não se reduz ao domínio dos conhecimentos, capacidades, destrezas e técnicas, mas trata-se, essencialmente, de saber mobilizar); do sujeito e do conteúdo (a competência só pode ser entendida por referência ao sujeito e ao contexto onde este se situa); do saber-integrar (a competência combina diversos elementos que se conjugam para a realização de uma tarefa ou resolução de um problema); da responsabilidade e do individual e do coletivo (a competência deve ser entendida numa perspetiva individual que comporta uma vertente coletiva). Para Courtois (1996) é esta dimensão coletiva que possibilita a construção de novos modos de ação, mais ajustados e inovadores.

Zarifian (1999) evidencia três aspetos que introduzem um caráter dinâmico na noção de competência:

i) a imprevisibilidade (incidente), considerada, pelo autor, ser relativa a ocorrências que perturbam o normal desenrolar do sistema, afetando a capacidade rotineira de assegurar a sua autorregulação. Alguém competente consegue, na ação, mobilizar os recursos necessários para resolver as novas situações problemáticas que possam surgir;

ii) a compreensão dos contextos, onde a comunicação surge como meio para compreender o outro e a si mesmo. A comunicação é importante enquanto potenciadora de diálogo e de construção do conhecimento acerca dos contextos; e

iii) a multiplicidade de funções associadas à profissão, evidenciando o caráter de construção permanente da competência profissional face a uma situação profissional cada vez mais mutável.

Para Dolz e Ollagnier (2004), o conceito de competência refere-se "às capacidades de diferenciação, adaptação, integração e combinação" (p. 4) e, nesse sentido, e no seguimento da ideia de saber combinatório de Le Boterf, constitui um continuum que se organiza à volta de saberes teóricos, sendo, assim, um sistema complexo funcional.

Spencer e Spencer (cit. em Ramos \& Bento, 2006) servem-se da imagem de um iceberg para explicitar o seu entendimento conceptual de 
competência. De acordo com os autores, a zona emersa do iceberg representaria os outputs da competência (habilidades e conhecimentos) e a submersa os inputs (motivações, traços, valores e autoconceito). Embora perspetivem a competência com um caráter dinâmico e evolutivo, consideram que é mais fácil intervir sobre os outputs, que se manifestam através de comportamentos e de ações, do que nos inputs, que se relacionam com as características da personalidade dos indivíduos.

O entendimento de competência de Perrenoud $(1999,2000)$ vem reforçar algumas das principais ideias supramencionadas, aproximando-se do de Le Boterf (embora este último esteja mais ligado ao campo das competências profissionais): a competência é entendida como o agir face a situações complexas, perante as quais é necessário tomar decisões e resolver problemas através da mobilização de um conjunto de recursos. "A abordagem por competências transforma saberes disciplinares em recursos para resolver problemas, realizar projectos e tomar decisões" (Perrenoud, 2001, cit. em Cachapuz et al., 2004, p. 23). A competência é definida pelo autor como um saber em ação, isto é, que se manifesta no agir, num contexto específico, mas sem se limitar à ação passível de ser observada. É, assim, um saber que se traduz na capacidade efetiva de utilização e de manejo intelectual, verbal ou prático -, e não nos conteúdos acumulados, com os quais não é possível agir no concreto nem fazer qualquer operação mental ou de resolução de problemas (Roldão, 2005a). Perrenoud (2001, pp. 133-144) considera, ainda, a autonomia fundamental em termos de educação e desenvolvimento. O seu entendimento de competência assenta, também, na necessidade de desenvolver sujeitos autónomos, capazes de agir por si, em contextos sociais distintos.

Allal (2004) considera os componentes afetivos, e também sociais, imprescindíveis a uma nova compreensão da noção de competência perspetiva-se uma visão mais humanizada do conceito. Para a autora, a competência "é uma rede integrada e funcional constituída por componentes cognitivos, afectivos, sociais, sensoriomotores, capaz de ser mobilizada em acções finalizadas diante de uma família de situações" (p. 15). A este propósito, Sá-Chaves (2005) e Tomaz (2007) sugerem uma visão expandida da noção de competência, na qual "se reconhecem componentes de natureza técnica, relacional, crítica e ética, pressupondo desde logo que o seu 
desenvolvimento constitui uma difícil e longa aprendizagem correspondente ao processo global de formação ao longo da vida" (Sá-Chaves, 2005, p. 9).

Roldão (2005a), como Perrenoud e Le Boterf, entre outros, também se refere ao conceito de competência como um saber em uso. Na perspetiva da autora, o uso integrado do saber situa-se no domínio da ação em diferentes campos da vida social e individual dos cidadãos e nos quais é necessário usar o saber para agir inteligentemente. Na mesma linha de pensamento situamse Galvão e colaboradores (Galvão et al., 2006), entendendo que a competência congrega a faculdade de mobilizar diferentes saberes adquiridos num novo espaço de ação, isto é, as competências, possuindo caráter operatório e social, são relativas a uma determinada situação e combinam de forma dinâmica os diferentes elementos que a constituem.

Para Leitão \& Alarcão (2006), uma definição possível é a veiculada pelo projeto DeSeCo (2002), que entende a competência como a capacidade de responder às exigências individuais ou sociais, ou de efetuar uma tarefa com sucesso, comportando dimensões cognitivas e não cognitivas. Rychen e Tiana (2005) vão ao encontro deste entendimento, considerando que o conceito de competência pode ser definido como uma combinação de conhecimentos, motivações, valores e ética, atitudes, emoções e de outros elementos sociais e comportamentais que, juntos, poderão ser mobilizados para o agir eficaz.

Zabala e Arnau (2007) entendem que a competência "é a capacidade ou habilidade (a existência nas estruturas cognitivas do sujeito de condições e recursos para atuar) de efectuar tarefas ou fazer frente a situações diversas (assumir um papel determinado; uma tarefa específica; realizar acções;...) de forma eficaz (capacidade efectiva; conseguir resultados e exercê-los excelentemente)" (p. 43)

Estas abordagens integradas, por procurarem ser mais abrangentes no fornecimento de elementos de compreensibilidade da competência (Pires, 2005), situam-se na linha da complexidade e da sistémica. De acordo com Hager e Gonczi (1996), estas abordagens perspetivam as competências como combinações complexas de elementos (conhecimentos, atitudes, valores e perícias) que são usados para compreender e funcionar em situações particulares em que os indivíduos se situam. Para os autores, esta abordagem permite, ainda, "incorporar aspectos éticos e valores como 
elementos do desempenho competente, a necessidade de prática reflectida, a importância do contexto e o factor de poder existir mais do que uma forma de poder exercer competentemente" (p. 249).

\section{Divergências e consensos na definição de competência}

Uma análise sistemática das abordagens teóricas e conceptuais existentes sobre o conceito de competência permitiu identificar, por um lado, imprecisões e/ou indefinições terminológicas relativas ao conceito de competência e, por outro, consensos, entre vários autores, quanto aos componentes e constituintes teóricos essenciais numa perspetiva integrada e holística de competência. A sistematização que se segue não pretende separar as partes (elementos analisados) do todo que define o conceito, somente contribuir para um entendimento e criação de uma linguagem comum no domínio de um referencial competencial.

\subsection{Imprecisões terminológicas na definição do conceito de competência}

Embora o presente estudo se tenha focado na análise crítica das definições e interpretações conceptuais de competência no domínio da Educação, foi possível identificar, entre os autores analisados, variações e imprecisões quanto à terminologia usada para a designação de uma mesma realidade ou, pelo menos, de realidades semelhantes - isto é, autores que partilham um entendimento do conceito de competência mas que, do ponto de vista da terminologia, o definem de forma distinta.

Focando o domínio da Educação, o conceito de competência surge identificado, na bibliografia de referência, com os conceitos de capacidade, saber (em ação, em uso, combinatório, complexo, integrado, dinâmico), processo, rede/sistema, dimensão de inteligência prática, coleção de recursos e pré-requisito. No sentido da clarificação dos conceitos supracitados, evidenciaremos, de seguida, os entendimentos avançados por diferentes autores para cada um destes conceitos. 


\section{Capacidade}

Vários são os autores que utilizam, na definição do seu entendimento do conceito de competência, os termos capacidade e competência como sinónimos. Rychen \& Tiana (2005) apresentam a definição do conceito de competência concebida no âmbito do projeto DeSeCo, entendida como "a capacidade de satisfazer com sucesso exigências complexas, ou ainda desenvolver uma determinada actividade ou tarefa" (pp. 33-34). Dolz e Ollagnier (2004) consideram que o conceito de competência se refere à combinação de diferentes capacidades (diferenciação, adaptação, integração e combinação), constituindo-se, assim, como um sistema complexo funcional.

Para Escamilla, Lagares e Fraile (2006), as competências são "capacidades relacionadas, de maneira prioritária, com o saber-fazer" ( $p$. 112). A este propósito, os autores esclarecem que a consideração da funcionalidade da competência não a reduz a um caráter meramente mecânico. No seu entendimento, o saber-fazer possui, também, uma dimensão de caráter teórico-compreensivo e uma dimensão de caráter atitudinal.

Pérez Gómez (2007) entende que as competências são capacidades para enfrentar exigências externas e desenvolver atividades e projetos de maneira satisfatória em contextos complexos. Naumescu (2008) considera que a competência é um conceito que integra "a capacidade para transferir capacidades e conhecimentos a situações e ambientes novos" (p. 5), acrescentando o desempenho das tarefas esperadas no local de trabalho como manifestação evidente da competência - ideia já evidenciada por Pellerey (2001), para quem ser competente não significa apenas o domínio dos conhecimentos e dos métodos, mas também a capacidade de integrar diferentes tipos de conhecimento e de os usar sinergeticamente. Para o autor, ser competente numa determinada área implica a capacidade de mobilizar o conhecimento e de o transformar em ações concretas.

Embora na maior parte das situações nos tenhamos deparado com imprecisões relativamente ao uso do termo capacidade na definição do conceito de competência, alguns autores evidenciam preocupação com o rigor, apresentando o seu entendimento sobre o conceito em causa. No sentido de ajudar a esta distinção, Perrenoud (2001) propõe o uso da palavra 'capacidade' quando se pretendem designar operações que não consideram 
o conjunto de uma situação e que ficam relativamente independentes dos contextos. De acordo com o autor, a utilização do termo competência deverá ser feita quando se pretendem designar disposições que subentendem a gestão global de uma situação complexa e contextualizada.

Gaspar (2004), no sentido de clarificação dos termos que, geralmente, se utilizam como sinónimos de capacidade, propõe a definição de habilidade como "actividade rotineira, automatismo, muitas vezes sensório motor, que se reporta a uma operação específica - vulgarmente associado a um saberfazer; ou, então, é algo adquirido através de uma habilitação" (p. 58). Por aptidão, a autora entende "um conjunto de disposições físicas e intelectuais, inatas ou adquiridas, para uma pessoa realizar uma tarefa. A aptidão é identificável e independente do contexto" (p. 58).

Saber (em ação, em uso, combinatório, complexo, integrado, dinâmico)

Para Perrenoud $(1999,2000)$, a competência é definida como um saber em ação. Isto é, a competência manifesta-se na ação, num contexto específico. Relativamente à oposição entre as noções de competência e de saber, Perrenoud assume uma posição aparentemente contraditória. Se, por um lado, o autor considera que esta oposição pode ser justificada na medida em que não é possível desenvolver competências a partir do conhecimento estruturado em disciplinas, por outro, considera que esta oposição também pode não se justificar uma vez que não é possível falar em competências sem falar em saberes (a maior parte das competências tem como pressuposto básico a aquisição de saberes).

Para Legendre (2000), a competência é entendida como um "saber agir fundado na mobilização e utilização eficaz dos recursos, que integra tanto os conhecimentos como outros recursos, e que está ligada aos contextos de exploração e às condições da sua aplicação fecunda". Fleury e Fleury (2001) definem a competência como um saber agir responsável e reconhecido, que implica mobilizar, integrar e transferir conhecimentos, recursos e habilidades.

Esta ideia do saber orientado para a ação é também partilhada, entre outros, por: Cachapuz, Sá-Chaves \& Paixão (2004), que entendem "os saberes como competências fundacionais que se deseja que todos os 
cidadãos na sociedade da informação e do conhecimento possuam" (p. 17); Pires (2005), que considera que a competência é composta por saberes de natureza diversa, que se finalizam na ação através da realização de tarefas em contextos determinados; Zabala e Arnau (2007), que consideram que a "competência consiste na intervenção eficaz nos diferentes âmbitos da vida mediante acções nas quais se mobilizam, ao mesmo tempo e de maneira inter-relacionada, componentes atitudinais, procedimentais e conceptuais" ( $p$. 45); Escamilla (2009), que define competência como "saber orientado para a acção eficaz, fundamentado numa integração dinâmica de conhecimentos e valores e desenvolvido mediante tipos de tarefas que permitem uma adaptação ajustada e construtiva a diferentes situações em contextos distintos" (p. 43); e Roldão (2005a), para quem a competência é um saber em uso.

Embora a definição do conceito de competência como processo, rede ou sistema, dimensão de inteligência prática, coleção de recursos e/ou conjunto de pré-requisitos tenha menos expressão na literatura consultada, num estudo que tem como finalidade contribuir para a clarificação do conceito de competência não poderia deixar de ser feita uma sistematização dos entendimentos emergentes do quadro teórico de referência. Assim:

\section{Processo}

Para Tóbon et al. (2006, cit. em Escamilla, 2009), as competências são processos complexos de desempenho (entendido como um todo sistémico, tendo como referência a realização de atividades e a resolução de problemas em diferentes contextos) que implicam idoneidade e responsabilidade. $\mathrm{Ou}$ seja, face a qualquer situação ou contexto, e considerando a finalidade a que se propõe, os autores consideram que o sujeito deverá pensar sobre a adequação da ação que pretende concretizar e avaliar todas as possíveis consequências.

\section{Rede/sistema}

A ideia de competência enquanto sistema complexo ou rede integrada e funcional é partilhada por Hager e Gonczi (1996), Weinert (2001), Jonnaert (2002), Allal (2004), Dolz \& Ollagnier (2004) e Le Boterf (2005), entre muitos 
outros. Para estes autores, a competência, promovendo a articulação entre domínios distintos, constitui-se como um saber combinatório, composto por diferentes componentes (ex. cognitivo, afetivo, sensoriomotor) e mobilizável em situações diversas.

\section{Dimensão de inteligência prática}

Canto \& Dupuy (2001), referindo-se às competências básicas, consideram que estas devem ser concebidas como dimensões da inteligência prática. Para os referidos autores, as competências básicas não devem ser percebidas como separadas e distintas, mas cada competência deve ser vista como um conjunto de competências.

\section{Coleção de recursos}

Pellerey (2001) define competência como uma coleção de recursos (conhecimento, saber-fazer, saber-ser) mobilizados para resolver problemas num contexto particular. Esta ideia é partilhada por Jonnaert (2002), que define as competências como a forma como cada sujeito gere os seus recursos cognitivos e sociais na ação, numa dada situação. Para o autor, cada competência faz referência a um conjunto de recursos que o sujeito pode mobilizar para resolver, com sucesso, determinada situação.

\section{Pré-requisitos}

Weinert (2001) considera que "o conceito de competência só deve ser usado para nos referirmos a pré-requisitos colocados à disposição de um indivíduo ou grupo de indivíduos de forma a ultrapassarem com sucesso exigências complexas" (p. 62).

Em síntese, embora seja evidente, entre os autores referidos, uma imprecisão terminológica no que se refere ao conceito de competência, na maior parte dos conceitos apresentados esta diversidade terminológica refere-se ao mesmo entendimento conceptual do objecto (competência). Assim, o entendimento conceptual emergente da análise realizada assenta em pilares conceptuais partilhados pelos vários autores. São estas convergências que abordaremos de seguida. 


\subsection{Convergências na definição de competência}

$\mathrm{Na}$ análise realizada às diversas abordagens do conceito de competência, foi, ainda, possível identificar entendimentos quanto a algumas características presentes na definição deste conceito. Assim, a competência:

\section{i) é constituída por diferentes elementos}

Embora sejam identificados, pelos vários autores, diferentes elementos constituintes das competências, existe acordo quanto à diversidade de elementos presentes. Ou seja, embora seja evidente na literatura a multiplicidade e imprecisão terminológica na definição dos elementos que constituem a competência, é consensual a pluralidade de elementos na sua constituição.

Assim, foram identificados na literatura como elementos integrantes da competência: saber; saber-fazer; saber-ser (Escamilla, 2009; Pellerey, 2001); habilidades, conhecimentos, motivações, traços, valores e autoconceito (Spencer \& Spencer, cit. em Ramos \& Bento, 2006); saber agir, querer agir e poder agir; conhecimentos, capacidades, destrezas e técnicas (Le Boterf, 2005); componentes cognitivos, afetivos, sociais e sensoriomotores (Allal, 2004; Legendre, 2000; Jonnaert, 2002); saberes de natureza diversa (Pires, 2005); conhecimentos, atitudes, valores e perícias (Hager \& Gonczi, 1996); conhecimentos, habilidades práticas, atitudes, valores e emoções (Pérez Gómez, 2007); conhecimentos, recursos e habilidades (Fleury \& Fleury, 2001); conhecimentos, capacidades, saberes-fazer, habilidades ou skills (Esteves, 2009); conhecimentos, emoções, atitudes, estratégias (Weinert, 2001); conhecimentos, atitudes práticas e cognitivas, conhecimento, motivação, valores, ética, emoções, componentes de caráter social e comportamental (OECD, 2002); conhecimentos, capacidades, atitudes e estratégias (Cachapuz et al., 2004); conhecimentos, capacidades e atitudes (Comissão Europeia, 2007; Ministério da Educação, 2001).

\section{ii) é pluridimensional}

Numa perspetiva integrada de competência, a multidimensionalidade é um aspeto consensual na literatura de referência. Embora possam ser encontradas designações distintas para a mesma dimensão, as dimensões 
cognitiva, sensoriomotora, social/coletiva, situacional, valorativa, afetiva e ética estão presentes na maioria dos documentos consultados.

As dimensões cognitiva, social/coletiva e situacional da competência são as mais evidenciadas, sendo assumidas pela maioria dos autores (Allal, 2004; Alonso, 2006; Cachapuz et al., 2004; Escamilla, 2009; Galvão et al., 2006; Hager \& Gonczi, 1996; Jonnaert, 2002; Katz, 2000; Le Boterf, 2005; Muller, 2003; Naumescu, 2008; Perrenoud, 1999, 2000; Roldão, 2005a; Weinert, 2001; entre muitos outros) e estando presentes nos principais documentos, nacionais e internacionais, orientadores da implementação em contexto escolar do enfoque competencial (Cachapuz et al., 2004; Comissão Europeia, 2007; OECD, 2001, 2002, 2004; Eurydice European Unit, 2002; González \& Williams, 2009).

As dimensões relacionadas com a ética, os afetos e os valores surgem em perspetivas de competência mais recentes (Allal, 2004; Alonso, 2006; Escamilla, 2009; Pérez Gómez, 2007; Naumescu, 2008; Rychen \& Tiana, 2005; Sá-Chaves, 2005; Tóbon et al., 2006, cit. em Escamilla, 2009), evidenciando o impacte da conjetura mundial atual na necessidade de uma visão mais humanizada do conceito.

A pessoalidade da competência é, ainda, evidenciada por Le Boterf (2005), Mayer (2000), Pellerey (2001) e Sá-Chaves (2005) de forma explícita, embora possa ser percebida/inferida em muitas outras das definições referidas.

\section{iii) é complexa}

A complexidade da competência está presente nas definições avançadas por vários autores. Para Escamilla (2009), a competência é definida como saber complexo, para Alonso (2006) implica a construção e transformação do conhecimento complexo, e Perrenoud (1999, 2001) entende-a como o agir face a situações complexas. Embora estes três autores integrem a complexidade no seu entendimento da definição de competência, fazem-no de forma distinta: a primeira autora referida considera o saber complexo como a essência da competência; a segunda refere-se à necessidade de transformação do conhecimento complexo para a construção da competência; e o último evidencia a complexidade das situações. 


\section{iv) é mobilizável e transferível}

A mobilização de múltiplos elementos e a possibilidade de transferência desses elementos para novas e diversas situações são características de competência evidenciadas como fundacionais na literatura de referência que advoga uma perspetiva integrada da noção de competência (Allal, 2004; Alonso, 2006; Escamilla, 2009; Esteves, 2009; Fleury \& Fleury, 2001; Galvão et al., 2006; Gaspar, 2004; Jonnaert, 2002; Le Boterf, 2005; Legendre, 2005, cit. em Almeida, 2009); Naumescu, 2008; Perrenoud, 1999, 2000; Roldão, 2005a; Rychen \& Tiana, 2005, entre outros). Le Boterf (2005) considera mesmo que a mobilização constitui a própria essência da competência. É a convocação e articulação dos múltiplos saberes face a uma determinada situação que, de acordo com o autor, indicia a competência. Tal ideia é partilhada por Esteves (2009), que a evidencia como diferenciadora dos elementos constitutivos da competência face a uma situação contextualizada. A este propósito, Roldão (2005b) define a transposição como a capacidade de transpor saberes de um domínio para outro ou, por outras palavras, do campo conceptual para o acional. Para a autora, a transposição é dependente do contexto e a competência não é viável sem um contexto, face ao qual a mobilização de saberes é acionada.

\section{v) é um saber em uso}

A definição da competência como o uso integrado do saber situa-se no domínio da ação (Roldão, 2005b), sendo este uso uma característica aceite de forma transversal, tanto no que diz respeito à evolução temporal do conceito como aos diferentes domínios em que esta ocorreu.

Face à divagação terminológica e conceptual associada à definição de competência enquanto saber em uso (Alonso, 2006; Roldão, 2005a), saber em ação (Jonnaert, 2002; Pérez Gómez, 2007; Rychen \& Tiana, 2005; Weinert, 2001), disposição para agir (Le Boterf, 2005; Perrenoud, 1999, 2000) e/ou saber orientado para a ação (Escamilla, 2009; Pires, 2005), Roldão (2005a) clarifica a distinção entre saber em uso e uso do saber. Para a autora, no plano epistemológico, a ideia do uso (diferente da aplicação ou ação) é inerente à própria natureza do saber. O conhecimento implica capacidade e possibilidade de uso, ou não pode considerar-se verdadeiro conhecimento. 
Opõe-se ao saber inerte, desprovido de sentido e vazio de potencialidades. Relativamente ao uso do saber, e de modo a não restringir a ideia de uso ao campo da estrita aplicação, a autora clarifica campos de possibilidade de usos do saber: i) o estabelecimento de nexos inteligentes de vária ordem (entre o real e o sujeito, entre o mundo introspetivo e o mundo da ação, entre o saber e a realidade, entre os contextos, entre os saberes entre si); ii) o uso do saber para poder agir inteligentemente, identificando a natureza da ação, dos seus propósitos, o seu contexto, e assim poder regular adequadamente o seu desenvolvimento; iii) o uso do saber para pensar, para interpretar, para compreender, ou seja, para poder conhecer mais e melhor, e para poder fundamentar o pensamento, o argumento, a decisão; e iv) a fruição. O saber que realmente se adquire permite-nos ganhos acrescidos, não só de acesso a novo conhecimento, mas de apreciação, satisfação, capacidade de prazer e entendimento no domínio cultural.

\section{vi) é de natureza combinatória}

A natureza combinatória da competência é outra das características consensuais para a definição deste conceito, sendo evidenciada pela maioria dos autores e estando presente nos principais documentos de referência para a definição e seleção das competências.

Le Boterf (2005) define a competência como saber combinatório - a competência combina diversos elementos que se conjugam para a realização de uma tarefa ou resolução de um problema - que pode ser entendido à luz do triângulo saber agir, querer agir e poder agir. Para este autor, a noção de competência deverá promover a articulação entre diversos domínios, nomeadamente: dos saberes e da ação; do sujeito e do conteúdo; do saber integrar; da responsabilidade e do individual e do coletivo.

Hager \& Gonczi (1996) perspetivam as competências (focando o plural do conceito) como combinações complexas de elementos (conhecimentos, atitudes, valores e perícias), que são usadas pelos indivíduos para compreender e funcionar nas diversas situações com que se deparam ao longo da vida.

Para Escamilla (2009), a competência fundamenta-se numa integração dinâmica de conhecimentos e valores, ideia que Galvão et al. (2006) também 
assumem quando se referem à combinação de forma dinâmica dos diferentes elementos que constituem a competência. Na mesma linha, Pellerey (2001) evidencia que ser competente implica a capacidade de integrar diferentes tipos de conhecimento e de os usar sinergeticamente.

A natureza combinatória da competência é, ainda, evidenciada por Pires (2005), que a define como "composta por saberes de natureza diversa, que se finalizam na acção, através da realização das tarefas num determinado contexto. Ela vai-se construindo e desenvolvendo na e pela ação" (p. 291).

Em síntese, embora seja evidente, entre a literatura considerada, a imprecisão terminológica que caracteriza a designação do conceito de competência, emerge um consenso quanto aos elementos que devem ser considerados na sua definição conceptual. Ao longo desta análise tornou-se evidente que a maioria dos autores referidos entende a competência como plural, no que diz respeito aos elementos que a constituem, pluridimensional, complexa, um saber em uso, mobilizável e transferível e de natureza combinatória.

\section{Conclusão}

A finalidade do estudo que se apresenta é, tal como já foi referido, contribuir para a clarificação conceptual da noção de competência. Neste sentido, foi feita uma síntese da evolução do conceito de competência e apresentadas e discutidas perspetivas de vários autores e orientações de organizações internacionais para uma abordagem integrada e sistémica do conceito.

A primeira conclusão que pode ser retirada da análise apresentada relaciona-se com a imprecisão conceptual e terminológica existente, no domínio educativo, quanto à definição da noção de competência. Mesmo entre autores que partilham uma perspetiva integrada e sistémica, são evidentes os distintos entendimentos encontrados para o conceito. Se ao nível da análise semântica é possível encontrar consensos quanto às principais características da competência - é um saber em uso (orientado para a ação), constituída por diferentes elementos, pluridimensional, complexa, dinâmica e interativa, de natureza combinatória, transferível e 
mobilizável para contextos distintos -, ao nível da análise estrutural, verificase uma grande diversidade na identificação e definição dos elementos que a compõem. Assim, a competência surge definida como capacidade, aptidão, habilidade, comportamento, saber, processo, rede, sistema, coleção de recursos e pré-requisito. Embora em muitas situações estas designações se refiram à mesma realidade, esta diversidade evidencia a necessidade de a comunidade científica se ocupar (de forma intencional e sistemática) da clarificação conceptual de cada um destes termos utilizados para definir competência, bem como das suas implicações epistemológicas e pedagógicas, no sentido da criação de um entendimento refletido e partilhado deste conceito, e que possa conduzir a uma desejável e necessária convergência de linguagem.

Outra conclusão importante prende-se com o impacte da imprecisão conceptual na atual orientação internacional de reorganização curricular com base no enfoque competencial. Nos últimos anos tem-se assistido, tanto a nível político como académico, a um esforço de identificação e definição consensual de competências, reconhecidas como básicas, essenciais e/ou fundamentais, que se deseja que todos os cidadãos possuam no século XXI. A urgência de dotar os indivíduos de competências, não apenas de caráter técnico, mas também de caráter pessoal e relacional, que permitam a sua adaptação a um mundo complexo, caracterizado pela imprevisibilidade e incerteza, é internacionalmente reconhecida. Projetos como o Tuning, de 2000 (González \& Wagenaar, 2003), ou o DeSeCo (OECD, 2002) evidenciam esta preocupação de chegar a um entendimento partilhado do que define e constitui a competência e de quais são as competências que devem ser identificadas e definidas como essenciais, isto é, quais devem ser consideradas pelos currículos e, consequentemente, pela escola, como saberes para todos (Cachapuz et al., 2004).

A emergência do conceito de competência no quadro da política internacional e ao nível da educação, em particular no desenvolvimento curricular, por um lado, e a discussão sobre a formação, ao nível do Ensino Superior induzida pelo processo de Bolonha, e seus impactes nas práticas dos professores, por outro, suscita, de acordo com Roldão (2005a, p. 10), perturbações associadas "ao efeito da discrepância face aos quadros curriculares de referência anteriores e a práticas de ensino ancoradas 
largamente num paradigma transmissivo". A reorganização curricular que atualmente se vive em diferentes países (a título de exemplo, em Espanha assistiu-se à reestruturação e reorganização do Sistema Educativo com a aprovação, em 2006, da Lei Orgânica da Educação [LOE] e no Reino Unido foi publicado pelo Ministério da Educação, em 2010, o National Curriculum Primary Handbook) e a resistência que, na prática, as suas implicações evidenciam são argumentos que reforçam a ideia da importância dos contributos da investigação para a clarificação conceptual da noção de competência enquanto referencial do currículo (nomeadamente, de acordo com os princípios de Bolonha). É, de facto, fundamental desenvolver e consolidar mais trabalho e mais discussão de forma a lidar eficazmente com a questão do desenvolvimento de competências no domínio da Educação.

\section{Referências}

Allal, L. (2004). Aquisição e avaliação de competências em situação escolar. In J. Dolz \& E. Ollagnier (Org.), O enigma da competência em educação (pp. 79-96). Porto Alegre: Artmed.

Alonso, L. (2006). Formação ao longo da vida e aprender a aprender. In Debate Nacional sobre Educação. Braga: Universidade do Minho.

Cachapuz, A., Sá-Chaves, I., \& Paixão, M. F. (2004). Saberes básicos de todos os cidadãos no século XXI. Lisboa: CNE.

Canavarro, J. (2000). Teorias e paradigmas organizacionais. Coimbra: Quarteto Editora.

Canto, M., \& Dupuy, J. P. (2001). Competencies for the good life and the good society. In D. Rychen \& L. Salganik (Eds.), Defining and selecting key competencies (pp. 67-92). Germany: Hografe \& Huber.

Comissão Europeia (2007). Competências essenciais para a aprendizagem ao longo da vida. Quadro de referência europeu. Luxemburgo: Serviço das Publicações Oficiais das Comunidades Europeias.

Courtois, B. (1996). Transformations de la formation et recompositions identitaire en enterprise. In J. Barbier, F. Berton \& J. J. Boru, Situation de travail et formation (pp. 165-201). Paris: L'Harmattan.

Delamare Le Deist, F., \& Winterton, J. (2005). What is competence? Human Resource Development International, 8(1), 27-47.

Delors, J., Mufti, I., Amagi, I., Carneiro, R., Chung, F., Geremek, B., ...Nanzhao, Z. (1996). Educação: Um tesouro a descobrir. Relatório para a UNESCO da Comissão Internacional sobre Educação para o século XXI. Porto: Edições ASA.

Dolz, J., \& Ollagnier, E. (2004). O enigma da competência. Porto Alegre: Artmed. 
Escamilla, A. (2009). Las competencias en la programación de aula. Infantil y Primaria (3-12 años). Barcelona: GRAÓ.

Escamilla, A., Lagares, A. R., \& Fraile, J. (2006). La LOE: Perspectiva pedagógica e histórica. Barcelona: GRAÓ.

Esteves, M. (2009). Construção e desenvolvimento de competências profissionais dos professores. Sísifo - Revista de Ciências da Educação, 8, 37-48.

Eurydice European Unit (2002). Key competencies: A developing concept in general compulsory education. Bruxelas: Eurydice.

Fleury, M. T., \& Fleury, A. (2001). Construindo o conceito de competência. Revista de Administração Contemporânea, edição especial, 183-196.

Galvão, C., Reis, P., Freire, A., \& Oliveira, T. (2006). Avaliação de competências em ciências. Sugestões para professores dos Ensinos Básico e Secundário. Porto: Edições ASA.

Gaspar, M. (2004). Competências em questão: Contributo para a formação de professores. Discursos (Série: Perspectivas em Educação), 55-71.

González, J., \& Wagenaar, R. (Ed.). (2003). Tuning educational structures in Europe. Retirado de http://www.tuning. unideusto.org

González, P., \& Williams, T. (Ed.). (2009). Highlights from TIMMS 2007: Mathematics and science achievements of U.S. fourth and eighth-grade students in an international context. Washington: National Center for Education Statistics.

Gouveia, J. (2007). Competências: Moda ou inevitabilidades? Saber (e) Educar, 12, 3158.

Hager, P., \& Gonczi, A. (1996). Professions and competencies. London: Routledge.

Jonnaert, P. (2002). Créer des conditions d'apprentissage. Une cadre de référence socioconstructiviste pour la formation des enseignants. Bruxelas: De Boeck

Katz, S. (2000). Competency, epistemology and pedagogy: Curriculum's holy trinity. The Curriculum Journal, 11(2), 133-144.

Le Boterf, G. (1999). De la compétence à la navigation professionnelle. Paris: Les Éditions de l'Organisation.

Le Boterf, G. (2005). Construir as competências individuais e colectivas. Lisboa: Edições ASA.

Legendre, M. F. (2000). Rencontre avec les responsables des programmes d'études et de l'évaluation du MEQ. In Ministère de L'Éducation du Québec (Org.), La logique des compétences. Sous différents aspectes. Session de formation des personnes-ressources, Saint-Hyacinthe.

Leitão, A., \& Alarcão, I. (2006). Para uma nova cultura profissional: Uma abordagem da complexidade na formação inicial de professores do $1^{\circ}$ CEB. Revista Portuguesa de Educação, 19(2), 51-84.

Mayer, R. (2000). Diseño educativo para un aprendizaje constructivista. In Ch. Reigeluth (Ed.), Diseño de instrucción, teorias y modelos. Madrid: Santillana.

McClelland, D. (1973). Testing for competence rather than for "intelligence". American Psychologist, January, 1-14. 
Ministère de l'Éducation du Québec (2001). Québec Education Program. Retirado de http://www.mels.gouv.qc.ca/DGFS/dp/programme_de_formation/primaire/pdf/ educprg2001.pdf

Ministério da Educação (Ed.). (2001). Currículo Nacional do Ensino Básico. Competências essenciais. Lisboa: Ministério da Educação, Departamento da Educação Básica.

Morin, E. (1999). Os sete saberes necessários à educação do futuro. Lisboa: Instituto Piaget.

Muller, F. (2003). Le concept. Retirado de http://francois.muller.free.fr/ diversifier/COMPETENCES.htm

Naumescu, A. (2008). Science teacher competencies in a knowledged based society. Acta Didactica Napocensia, 1(1), 25-31.

OECD (2001). Knowledge and skills for life: First results from PISA 2000. Paris: OECD Publications.

OECD (2002). Definitions and Selection des Competences (DeSeCo): Fondements theoriques. Retirado de http://www.portal-stat.adm.ch/deseco/deseco_doe_ strategique.pdf

OECD (2004). Messages from PISA 2000. Paris: OECD Publications.

Pellerey, M. (2001). Sul concetto di competenza ed in particolare di competenza sul lavoro. In C. Montedoro (Ed.), Dalla pratica alla teoria per la formazione: Un percorso di ricerca epistemologica (pp. 18-35). Milano: Franco Angeli.

Pérez Gómez, A. (2007). Las competências básicas y el currículo. Gobierno de Cantábria: Consejería de Educación.

Perrenoud, P. (1999). Construir as competências desde a escola. Porto Alegre: Artmed.

Perrenoud, P. (2000). Dez novas competências para ensinar. Porto Alegre: Artmed.

Perrenoud, P. (2001). The key to social fields: Competencies of an autonomous actor. In D. Rychen \& L. Salganik (Ed.), Defining and selecting key competencies (pp. 121-150). Seattle: Hogrefe \& Huber.

Pires, A. L. (2005). Educação e formação ao longo da vida: Análise crítica dos sistemas $e$ dispositivos de reconhecimento e validação de aprendizagens e de competências. Lisboa: FCG.

Ramos, E., \& Bento, S. (2006). As competências: Quando e como surgiram. In M. Ceitil, Gestão e Desenvolvimento de Competências (pp. 85-118). Lisboa: Edições Sílabo.

Roldão, M. C. (2003). Gestão do currículo e avaliação de competências. Porto: Edições ASA.

Roldão, M. C. (2005a). Para um currículo do pensar e do agir: As competências enquanto referencial de ensino e aprendizagem. En direct de l'APPF, 9-20.

Roldão, M. C. (2005b). Professores para quê? Para uma reconceptualização da formação de profissionais de ensino. Revista Discursos, 95-120.

Ropé, F., \& Tanguy, L. (1997). Saberes e competências: O uso de tais noções na escola e na empresa. Campinas: Papirus. 
Rychen, D., \& Salganik, L. (Eds.). (2001). Defining and selecting key competencies. Göttingen, Germany: Hogrefe \& Huber.

Rychen, D., \& Tiana, A. (2005). Desenvolver competências-chave em educação. Algumas lições extraídas da experiência nacional e da internacional. Porto: Edições ASA.

Sá-Chaves, I. (1994). A construção do conhecimento pela análise reflexiva da praxis (Tese de Doutoramento). Universidade de Aveiro, Aveiro.

Sá-Chaves, I. (2005). Os portfolios reflexivos (também) trazem gente dentro. Reflexões em torno do seu uso na humanização dos processos educativos. Porto: Porto Editora

Santos, M. (2005). Reforma da educação: O entendimento da complexidade pela busca do sujeito. Retirado de http://www.ufrrj.br/ leptrans/link/marciorayol.pdf

Silva, A. (2009). Novos saberes básicos dos alunos, novas competências dos professores (Tese de Doutoramento). Universidade de Aveiro, Aveiro.

Tardif, M. (1999). Saberes docentes e formação profissional. Rio de Janeiro: Vozes.

Tomaz, A. (2007). Supervisão curricular e cidadania: Novos desafios à formação de professores (Tese de Doutoramento). Universidade de Aveiro, Aveiro.

Weinert, F. (2001). Concept of competence: A conceptual clarification. In D. Rychen \& L. Salganik (Eds.), Defining and selecting key competencies (pp. 45-66). Seattle: Hogrefe \& Huber.

Zabala, A., \& Arnau, L. (2007). 11 ideas clave. Como aprender y enseñar competências. Barcelona: GRAÓ.

Zarifian, P. (1999). Objectif compétence. Paris: Liaisons. 


\title{
CONTRIBUTIONS TO COMPETENCE CONCEPT CLARIFICATION IN AN INTEGRATED AND SYSTEMIC APPROACH
}

\begin{abstract}
This article aims to be a contribute, through different authors' perspectives analysis (Allal, 2004; Alonso, 2006; Escamilla, 2009; Jonnaert, 2002; Le Boterf, 2005; Legendre, 2000; Perrenoud, 1999, 2001; Roldão, 2005a; Rychen \& Tiana, 2005; among others), to the competence concept clarification, assuming a concept integrated and systemic approach. Therefore, we intent to collaborate towards a global and integrative perspective clarification, that considers competence multiple dimensions, contents and elements for its shared use, in a more incident way in the education field. To this end, after a brief introduction, this article defends the importance of competence conceptual clarification, presents a brief competence concept evolution and systematizes the main differences and similarities found in the analyzed perspectives.
\end{abstract}

Keywords

Competence; Concept evolution; Integrated and systemic approach

CONTRIBUCIONES A LA CLARIFICACIÓN DEL CONCEPTO DE COMPETENCIA EN UNA PERSPECTIVA INTEGRADA Y SISTÉMICA

\section{Resumen}

En este artículo tenemos como principal objetivo contribuir, a través del análisis reflexiva de las perspectivas presentadas por diferentes autores (Allal, 2004; Alonso, 2006; Escamilla, 2009; Jonnaert, 2002; Le Boterf, 2005; Legendre, 2000; Perrenoud, 1999, 2001; Roldão, 2005a; Rychen \& Tiana, 2005; entre otros), para aclarar el concepto de competencia, asumiendo una perspectiva integrada y sistémica del concepto. Tenemos la intención de 
ayudar à la clarificación de una perspectiva global e integradora de este concepto, que asume sus múltiples dimensiones, contenidos y elementos, para su uso compartido más incidente en el campo de la educación. Para ello, tras de una breve introducción, se discute la importancia de la clarificación conceptual de la noción de competencia, se presenta una breve evolución del concepto y explora las principales diferencias y similitudes que se encuentran en el entendimiento avanzado por los autores analizados.

Palabras clave

Competencia; Evolución del concepto; Perspectiva integrada y sistémica

Recebido em Janeiro/2011 Aceite para publicação em Novembro/2012 